\title{
Lack of germline A339V mutation in thyroid transcription factor-1 (TITF-1/NKX2.1) gene in familial papillary thyroid cancer
}

\author{
Silvia Cantara, Serena Capuano, Caterina Formichi, Milena Pisu, Marco Capezzone, Furio Pacini*
}

\begin{abstract}
Thyroid cancer may have a familial predisposition but a specific germline alteration responsible for the disease has not been discovered yet. We have shown that familial papillary thyroid cancer (FPTC) patients have an imbalance in telomere-telomerase complex with short telomeres and increased telomerase activity. A germline mutation (A339V) in thyroid transcription factor-1 has been described in patients with multinodular goiter and papillary thyroid cancer. In this report, the presence of the A339V mutation and the telomere length has been studied in FPTC patients and unaffected family members. All samples analyzed displayed a pattern typical of the homozygous wild type revealing the absence of the A339V mutation. Shortening of telomeres was confirmed in all patients. We concluded that the A339V mutation in thyroid transcription factor-1 (TITF-1/NKX2.1) is not correlated with the familial form of PTC, even when the tumor was in the context of multinodular goiter.
\end{abstract}

\section{Findings}

Familial non-medullary thyroid cancer (FNMTC), most frequently of papillary hystotype (FPTC), recurs in two or more members of the same family in about $10 \%$ of the patients. The clinical form of PTC may be part of a clinical syndrome such as the Adenomatous polyposis of colon (FAP) [1], Cowden syndrome [2], Gardner syndrome [3], Werner syndrome [4] or Carney complex [5] or may be the only disease manifestation. In this case, the large majority of FPTC, no candidate gene(s) has been discovered [6]. Recently we provided evidence that FPTC display the feature of "genetic anticipation" (defined as earlier age at onset of the disease and/or increased severity in successive generations), and, at molecular level, are characterized by the presence of germinal alterations in the telomere-telomerase complex $[7,8]$. Our hypothesis is that the imbalance in telomerase complex may predispose to acquire a thyroid specific mutation able to trigger thyroid tumorigenesis. Recently, Ngan et al. demonstrated the presence of a new germline mutation (A339V) in thyroid transcription factor-1 (TITF-1/NKX2.1) in patients with multinodular goiter

\footnotetext{
* Correspondence: pacini8@unisi.it

Section of Endocrinology \& Metabolism, Department of Internal Medicine, Endocrinology \& Metabolism and Biochemistry, University of Siena, Siena, Italy
}

(c) 2010 Cantara et al; licensee BioMed Central Ltd. This is an Open Access article distributed under the terms of the Creative Commons Attribution License (http://creativecommons.org/licenses/by/2.0), which permits unrestricted use, distribution, and reproduction in any medium, provided the original work is properly cited. and papillary thyroid cancer [9]. The authors identified the mutation in four out of $20 \mathrm{MNG} / \mathrm{PTC}$ patients which developed more advanced tumors compared to MNG/PTC or PTC patients without the mutation. In addition, the mutation was dominantly inherited in two families with members bearing MNG/PTC [9].

In light of these evidences, we investigated the presence of $\mathrm{A} 339 \mathrm{~V}$ mutation in patients with the occurrence of FPTC and short telomeres. Out of 408 patients affected by differentiated thyroid carcinoma (DTC), followed in the Section of Endocrinology of University of Siena (Italy) from 1978 to 2009 (306 females and 102 males; ratio F/M: 3/1, ranging 8-84 yrs), 63 patients (15.4\%), belonging to 38 kindred, showed the familial recurrence of the disease possibly configuring the features of familial thyroid cancer (FTC). All patients with FTC had the papillary hystotype (FPTC), 15 of them (23.8\%) presented the follicular variant and $1(1.6 \%)$ the warthin-like variant. Of these patients, $40(63.4 \%)$ had a parent-child relationship (22 kindred), 19 (30.2\%) had a sibling relationship (13 kindred) and 4 (6.4\%) had an uncle-niece relationship (3 kindred). Age at diagnosis of FPTC group was $46 \pm 15.5$ yrs (range: $15-78$ yrs). Age at diagnosis of probands was $54.3 \pm 9.3$ (range 25-77 yrs) and that of affected familial members was $42.9 \pm 15.7$ (range 15-73 
Table 1 Clinical features of FPTC patients

\begin{tabular}{|c|c|}
\hline & Patients $(n=63)$ \\
\hline \multicolumn{2}{|l|}{ Age at diagnosis (yr) } \\
\hline Mean \pm SD & $46 \pm 15.5$ \\
\hline Range & $15-78$ \\
\hline \multicolumn{2}{|l|}{ Sex } \\
\hline No. of females (\%) & $47(74.6)$ \\
\hline No. of males (\%) & $16(25.4)$ \\
\hline \multicolumn{2}{|l|}{ Histotype } \\
\hline No. of papillary (\%) & $47(74.6)$ \\
\hline No. of papillary follicular variant (\%) & $15(23.8)$ \\
\hline No. of papillary warthin-like (\%) & $1(1.6)$ \\
\hline \multicolumn{2}{|l|}{ TNM } \\
\hline No. of T1-T3 N0 MO(\%) & $40(63.5)$ \\
\hline No. of T1-T3 N1 M0 (\%) & $13(20.6)$ \\
\hline No. of T1-T3 N0-N1 M1 (\%) & $1(1.6)$ \\
\hline No. of T4 No-N1 M0 (\%) & $3(4.7)$ \\
\hline Not available & $6(9.6)$ \\
\hline \multicolumn{2}{|l|}{ Outcome } \\
\hline Remission (\%) & 45 (71.4) \\
\hline Persistent disease (\%) & $12(19.1)$ \\
\hline Not evaluated (\%) & $6(9.5)$ \\
\hline
\end{tabular}

yrs). No thyroid cancer associated syndrome was present clinically in our patients. Clinical features of FPTC patients are reported in Table 1. In addition, we analyzed 41 unaffected family members of FPTC patients (14 males and 27 females, mean age: $44.4 \pm 19$ yrs, range: 14-62 yrs) belonging to 25 kindred. Among FPTC patients, 23 (36.5\%) had a single nodule whereas
$40(63.5 \%)$ patients had a history of multinodular goiter. At the time of the study $45(71.4 \%)$ were free of disease, 12 (19.1\%) showed persistent disease and 6 (9.5\%) were operated less than 1 year ago (follow-up not available). In the group of 41 unaffected family members, $33(80.6 \%)$ patients had no evidence of thyroid nodule, $4(9.7 \%)$ showed a multinodular goiter and $4(9.7 \%)$ had a single nodule. In all cases the FNAB indicated the presence of benign lesions. We measured telomere length by Q-PCR [10] assay on genomic DNA of all subjects and compared the differences in telomere length by Student's t-test. As shown in figure 1 , RTL was significantly $(\mathrm{p}<0.0001)$ shorter in FPTC patients (mean \pm SD: $0.8 \pm 0.04$, range: 0.18-2.4) compared to unaffected siblings (mean \pm SD: $2.04 \pm 0.2$, range: 0.7-7.6). To identify whether TITF/NKX2.1 germline point mutation (A339V) was involved with FPTC development, genomic DNA belonging to FPTC patients and unaffected siblings, was amplified using the GC-Rich PCR system followed by digestion of PCR products by restriction enzyme NaeI. This enzyme cut in correspondence of 5'-GCCGGC-3' sequence thus leading to the formation of these patterns: A) homozygous wild type characterized by three fragments of 421, 197 and $148 \mathrm{bp}$, respectively; B) mutated homozygous characterized by two PCR products of 618 and $148 \mathrm{bp}$, respectively and C) heterozygous characterized by four fragments at 618, 421, 197 and $148 \mathrm{bp}$, respectively. As shown in figure $2 \mathrm{~A}$, after digestion with the enzyme all the analyzed samples displayed a pattern typical of homozygous wild type. To confirm this

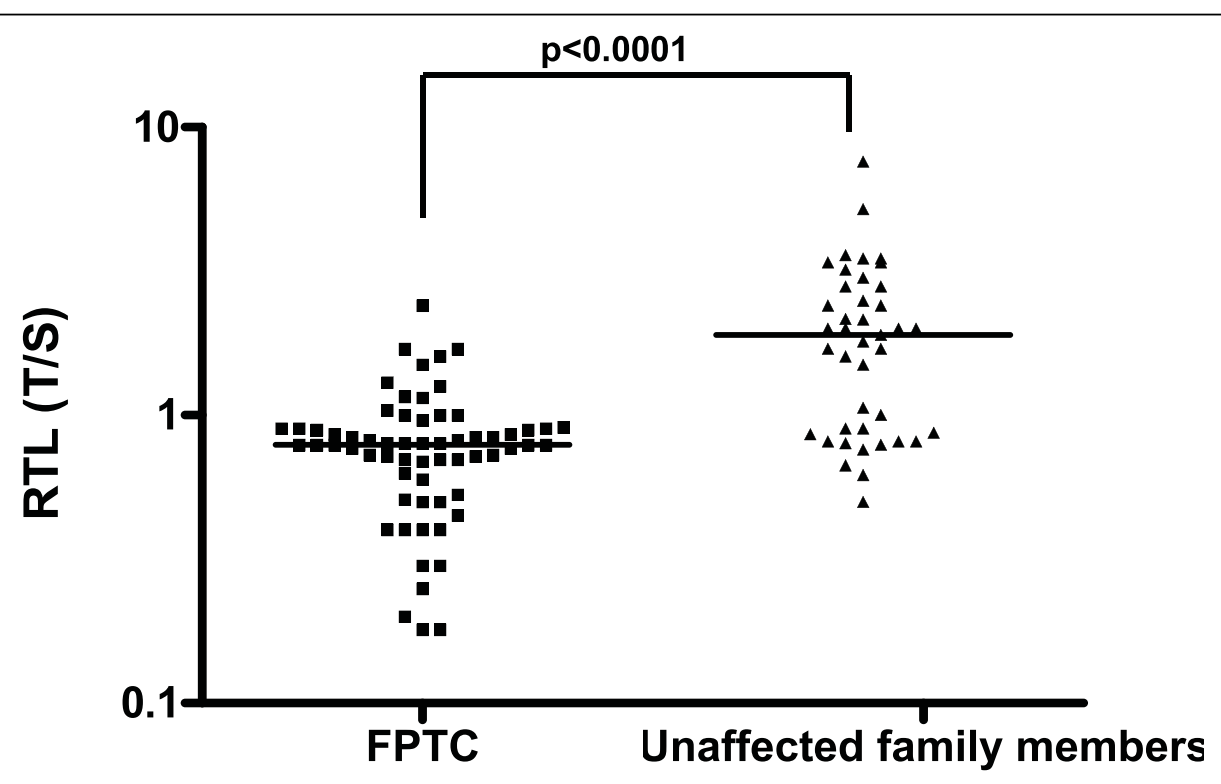

Figure 1 RTL expressed as T/S of 63 FPTC patients compared to 41 unaffected siblings Statistic by Student's t-test (A). 

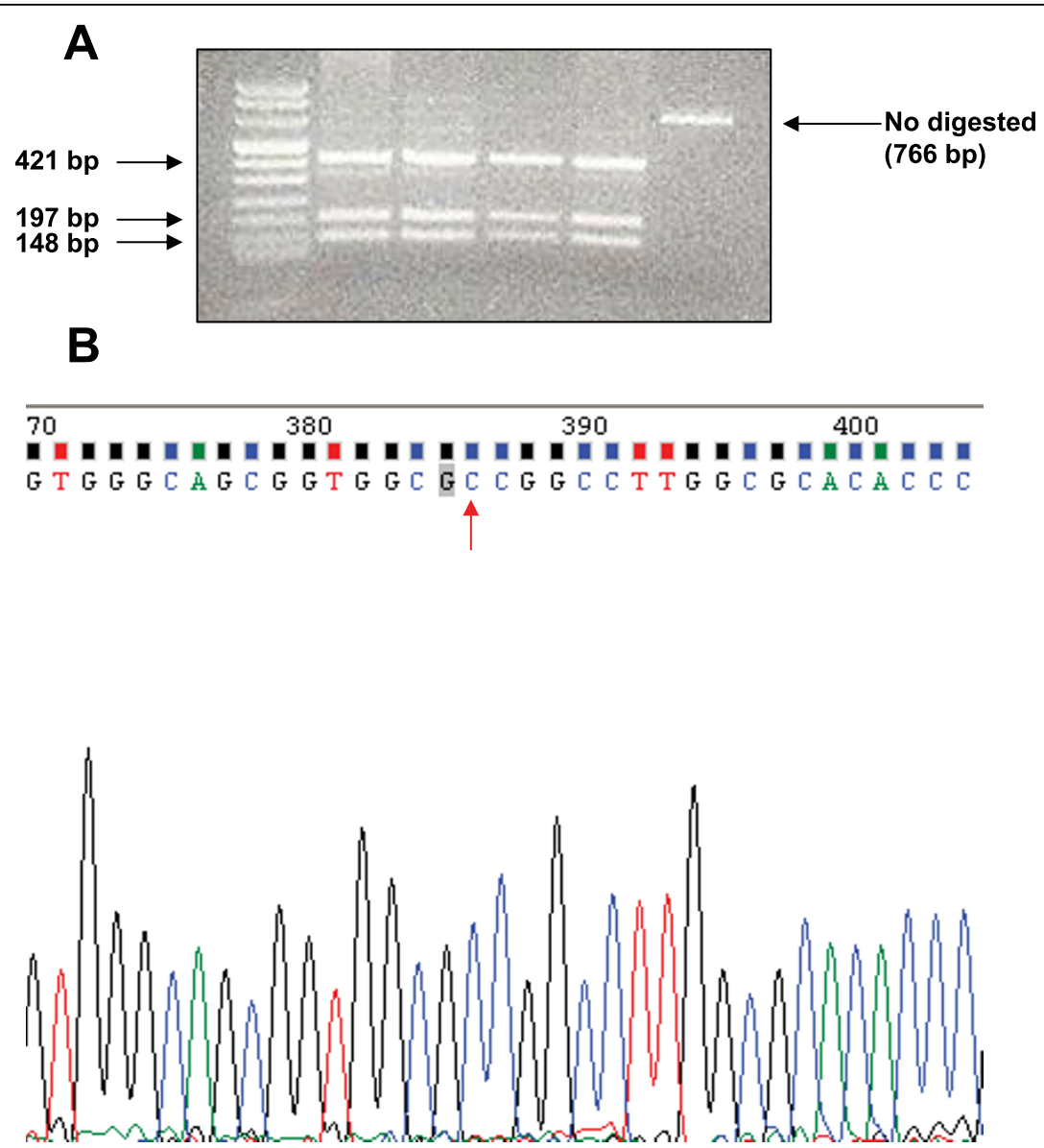

Figure 2 Representative gel illustrating the homozygous wild type digestion pattern showed by FPTC patient and unaffected siblings (A); Representative electropherogram of an FPTC patient showing the absence of mutation(s) in TITF/NKX2.1 gene (B).

result, samples were amplified twice and PCR products directly sequenced. As reported in figure $2 \mathrm{~B}$ no mutation was found in all samples.

In conclusions, in this study we analyzed 63 FPTC patients for the presence of the A339V mutation in thyroid transcription factor-1 (TITF-1/NKX2.1) in order to correlate that mutation with the predisposition to develop familial form of thyroid cancer demonstrated by shorter telomere length which may contribute to genetic instability and thyroid cancer development. Our results confirmed that FPTC patients have significantly short telomeres compared to unaffected family members. The reason of the predisposition to develop thyroid cancer in patients displaying the imbalance in telomerase complex has not been identified yet. The A339V mutation in thyroid transcription factor-1 (TITF-1/NKX2.1) might be a candidate gene in view of recent findings [9]. All FPTC patients displayed a genetic profile typical of homozygous wild type demonstrating that A339V mutation is not necessarily associated with the development of familial form of thyroid cancer even when the tumor was in the context of multinodular goiter.

\section{Authors' contributions}

SC carried out the molecular genetic studies and wrote the manuscript, SC contributed to perform the experiments, CF helped to collect clinical patient's data, MP helped with DNA extraction, MC revised the clinical data and FP revised the manuscript and coordinated the experiments.

All authors read and approved the final manuscript.

\section{Competing interests}

The authors declare that they have no competing interests.

Received: 5 July 2010 Accepted: 11 August 2010

Published: 11 August 2010

\section{References}

1. Giardiello FM, Offerhaus GJA, Lee DH, Krush AJ, Tersmette AC, Booker SV, Kelley NC, Hamilton SR: Increased risk of thyroid and pancreatic carcinoma in familial adenomatous polyposis. Gut 1993, 34:1394-1396.

2. Liaw D, Marsh DJ, Li J, Dahia PLM, Wang SI, Zheng Z, Bose S, Call KM,

Tsou HC, Peacocke M, Eng C, Parsons R: Germline mutations of the PTEN gene in Cowden disease, an inherited breast and thyroid cancer syndrome. Nat Genet 1997, 16:64-67. 
3. Kelly MD, Hugh TB, Field AS, Fitzsimons R: Carcinoma of the thyroid gland and Gardner's syndrome. Aust N Z J Surg 1993, 63:505-9.

4. Goto M, Miller RW, Ishikawa Y, Sugano H: Excess of rare cancers in Werner syndrome (adult progeria). Cancer Epidemiol Biomarkers Prev 1996, 5:239-246.

5. Stratakis CA, Courcoutsakies NA, Abati A, Filie A, Doppman JL, Carney A, Shawker T: Thyroid gland abnormalities in patients with the syndrome of spottyskin pigmentation, myxomas, endocrine overactivity, and schwannomas (Carney complex). J Clin Endocrinol Metab 1997, 82:2037-2043

6. Sturgeon C, Clark OH: Familial nonmedullary thyroid cancer. Thyroid 2005, 15:588-93.

7. Capezzone M, Marchisotta S, Cantara S, Busonero G, Brilli L, PazaitouPanayiotou K, Carli AF, Caruso G, Toti P, Capitani S, Pammolli A, Pacini F: Familial non-medullary thyroid carcinoma displays the features of clinical anticipation suggestive of a distinct biological entity. Endocr Relat Cancer 2008, 15:1075-81.

8. Capezzone M, Cantara S, Marchisotta S, Filetti S, De Santi MM, Rossi B, Ronga G, Durante C, Pacini F: Short telomeres, telomerase reverse transcriptase gene amplification, and increased telomerase activity in the blood of familial papillary thyroid cancer patients. J Clin Endocrinol Metab 2008, 93:3950-7.

9. Ngan ESW, Lang BHH, Liu T, Shum CKY, So MT, Lau DKC, Leon TYY, Cherny SS, Tsai SY, Lo CY, Khoo US, Tam PKH, Garcia-Barcelo MM: A Germline mutation (A339V) in thyroid transcription factor-1 (TITF-1/ NKX2.1) in patients with multinodular goiter and papillary thyroid carcinoma. JNCl 162-75, 101

10. Cawthon RM: Telomere measurement by quantitative PCR. Nucleic Acids Research 2002, 30:47.

doi:10.1186/1756-6614-3-4

Cite this article as: Cantara et al: Lack of germline A339V mutation in thyroid transcription factor-1 (TITF-1/NKX2.1) gene in familial papillary thyroid cancer. Thyroid Research 2010 3:4.

\section{Submit your next manuscript to BioMed Central and take full advantage of:}

- Convenient online submission

- Thorough peer review

- No space constraints or color figure charges

- Immediate publication on acceptance

- Inclusion in PubMed, CAS, Scopus and Google Scholar

- Research which is freely available for redistribution

Submit your manuscript at www.biomedcentral.com/submit
Biomed Central 